\title{
Influence of Inhomogeneity on Mechanical Properties of Commercially Pure Titanium Processed by HPT
}

\author{
Alexander P. Zhilyaevv ${ }^{1,2, a}$, Yi Huang ${ }^{3, b}$, Jose Maria Cabrera ${ }^{4, c^{*}}$ \\ and Terence G. Langdon ${ }^{3, d}$ \\ ${ }^{1}$ Laboratory of Mechanics of Gradient Nanomaterials, Nosov Magnitogorsk State Technical \\ University, Magnitogorsk, 455000, Russia \\ ${ }^{2}$ Institute for Metals Superplasticity Problems, Khalturina 39, Ufa, 450001, Russia \\ ${ }^{3}$ Materials Research Group, Department of Mechanical Engineering, University of Southampton, \\ Southampton SO17 1BJ, U.K. \\ ${ }^{4}$ Departamento de Ciencia de los Materiales e Ingeniería Metalúrgica, EEBE - Universitat \\ Politècnica de Catalunya, Barcelona, 08019, Spain \\ a alex.zhilyaev@hotmail.com, by.huang@soton.ac.uk, cjose.maria.cabrera@upc.edu, \\ dangdon@soton.ac.uk
}

Keywords: High pressure torsion, Ultrafine-Grained Materials, Titanium, Microstructure, Mechanical Properties.

\begin{abstract}
Already for fifteen years many researchers have been trying to discover metallic materials with unusual combinations of strength and ductility: with high strength and enhanced ductility. This combination may be achieved through different ways: alloying, nanostructuring, etc. This report is an attempt to analyze the influence of inhomogeneity of different types (structural, phase and space) on mechanical properties of commercially pure titanium (bulk and powder) subjected to high-pressure torsion. Experimental results for HPT bulk and powder titanium have demonstrated that mechanical behavior of CP titanium strongly depends on phase inhomogeneity (alpha + omega phases), structural inhomogeneity (bimodal grain size distribution) and space inhomogeneity (retained porosity) in case of cold consolidated Ti powder. High strength in HPT bulk titanium due to the formation of hard omega phase during HPT processing at room temperature was detected. The strong omega phase transforms back to nanograined alpha phase domains during short annealing at elevated temperature. HPT consolidation of titanium powder leads to the formation of brittle specimens showing high strength but almost zero plasticity.
\end{abstract}

\section{Introduction}

This intriguing story began almost 16 years ago, when Valiev and co-authors published a report [1] which has become highly cited to date. In this report the term "strength - ductility paradox" was firstly introduced for describing enhanced plasticity in HPT titanium processed for 5 whole revolutions compared to that processed for one revolution. Note that specimens had the same strength $(\sim 800 \mathrm{MPa})$ and they were tested at $\mathrm{T}=250{ }^{\circ} \mathrm{C}$. Moreover, the next year Valiev and coworkers published another report [2] showing that short annealing $(10 \mathrm{~min})$ at $300{ }^{\circ} \mathrm{C}$ of $\mathrm{HPT}$ titanium $(\mathrm{P}=5 \mathrm{GPa}, \mathrm{N}=7)$ with prior tensile testing increases strength and ductility simultaneously. Annealing at higher temperature $\left(350^{\circ} \mathrm{C}\right)$ leads to additional increase in ductility and strength. Since that time, numerous reports related to this phenomenon have been published (i.e. recent ones $[3,4,5,6]$ or readers may review the corresponding reference list in [7]). However, the materials under study were not limited to pure metals (copper and titanium as in original report [1]) but they were mostly expanded to alloys and metal-matrix composites or electrodeposited specimens. Processing routes were also not limited to equal channel angular pressing (ECAP) or HPT but also they involved different processing routes related to severe plastic deformation and including deformation at cryogenic temperatures [8]. There is no doubt that severe plastic deformation [9], especially the two main processing routines (equal channel angular pressing [10] and high pressure torsion [11]) allow fabricating unique microstructures and properties which are not only interesting 
from fundamental point view [7] but also suitable for practical applications [12]. Moreover, it is worth noting that strong materials with enhanced ductility have been a "desideratum" of Metallurgy and Materials Science for many years and researchers and developers have achieved amazing results by alloying and corresponding thermo-mechanical processing. It has to be clearly understood that only for pure metals the coupled phenomenon "strength-ductility" has a non-trivial meaning and it needs a reliable explanation. Most of the published reports having in the title or in the aims the term "strength-ductility" have dealt with alloys where desirable combination of strength and ductility can be achieved by regular thermo-processing.. Another issue when discussing pure metals is the fact of limited numbers of defects (vacancies, dislocations and grain boundaries) contributing to strain hardening. Obviously grain size refinement and increasing dislocation density during severe plastic deformation shall lead to enhance strength due to Hall-Petch and dislocation hardening and simultaneously decrease the ductility as the free path of dislocation gliding is shortened. Accordingly, to date no reliable explanations exist for the "strength-ductility" paradox, at least in pure metals. In order to explain "strength-ductility paradox" a few suggestions have been discussed in the literature. First introduced by Valiev more than 30 years ago [13], the concept of "non-equilibrium (NE)" grain boundaries which are characterized by enhanced GB energy due to dislocation absorption during SPD has been often discussed. It is worth noting that grain boundaries are non-equilibrium objects by definition and they have actually different specific surface energy depending on their characteristic parameters. However, one can speculate that non-equilibrium GBs are characterized by enhanced GB dislocation density and they may possess enhanced diffusivity, by analogy to the crystal lattice that may have enhanced diffusivity due to dislocations in grains interior making a contribution to the overall diffusion process. However, the activation energy of such NE boundaries cannot be lower that the activation energy for self-diffusion on the free surface. If the concept of NE boundaries is plausible then one may suggest that GB sliding can be involved for UFG materials as a reliable deformation mechanism which is characterized by high stress applied and it can provide sufficient ductility. Second possible explanation for enhanced strengthductility in UFG materials (at least for the case of short annealing) is the possibility for fast diffusion along GBs and the creation of a metal-titanium oxide composite. Titanium oxide particles located at GBs may contribute additional hardening and/or enhancing ductility. There is no underlying mechanism for this phenomenon. Third as suggested by Ma and co-authors [3, 8] for copper and nickel which possess heterogeneous microstructure consisting of large grains surrounding by small ones or vice versa. In this model large grains furnish enhanced ductility and small ones provide high strength. Although such kind of bimodal microstructure was detected in electrodeposited copper [8] and nickel especially after annealing when abnormal grain growth occurred [14] there is no such observation for severely deformed pure metals, at least for the temperature and time of short annealing. Summarizing all abovementioned, the aim of the present report is intended to examine the "strength-ductility paradox" for commercially pure titanium by (i) processing bulk CP titanium by HPT for 1 and 5 revolutions; (ii) perform short annealing at relatively low homologous temperature for 10 minutes, (iii) consolidate titanium powder at room temperature by HPT in order to obtain Ti-TiO composite and (iv) performing microstructural analysis and mechanical testing. It is expected that experimental results may give some information on an explanation of the "strength-ductility" phenomenon in UFG titanium.

\section{Experimental Methods and Materials}

The initial material used in the report $[1,2]$ was commercially pure titanium VT1-0. The closest material in terms of composition to Russian titanium VT1-0 is a commercial pure titanium Grade 2. Therefore, the experiments were conducted using CP grade2 titanium (99.3\% purity) that was purchased from GoodFellow ${ }^{\mathrm{TM}}$ in the form of rods having diameters of $10.0 \mathrm{~mm}$. These rods were annealed for $2 \mathrm{~h}$ at $973 \mathrm{~K}$ under an Ar-controlled atmosphere, furnace cooled and then cut into disks with thicknesses of $\sim 1 \mathrm{~mm}$. From the same company, powder of titanium (mesh $\sim 150 \mu \mathrm{m}$ ) was purchased for cold consolidation. Prior to HPT consolidation, the titanium powder was precompacted. The HPT facility operated under quasi-constrained conditions. All disks of bulk 
titanium were processed by HPT at room temperature under an applied pressure, $\mathrm{P}$, of $6.0 \mathrm{GPa}$, a rotation speed of $1 \mathrm{rpm}$ and torsional straining through numbers of revolutions, $\mathrm{N}$, of 1 and 5 turns. Titanium pre-compacts were densified using the HPT facility by applying a pressure of $6 \mathrm{GPa}$ and keeping it for 1 minute. Dense disks obtained from Ti powder further were processed under the same conditions as bulk titanium samples: $\mathrm{P}=6 \mathrm{GPa}$ and $\mathrm{N}=1$ and 5 whole revolutions. The microstructure analysis of bulk and densified Ti powder annealed in vacuum at $700{ }^{\circ} \mathrm{C}$ for one hour showed mean grain sizes of $142.8 \pm 48.2 \mu \mathrm{m}$ and $85.1 \pm 29.5 \mu \mathrm{m}$ for bulk and powder titanium, correspondingly. Grain size was measured by the intercept method using Image ${ }^{\mathrm{TM}}$ [15]. All disks were polished to a mirror-like quality and hardness measurements were taken using a Vickers micro-hardness tester with a load of $500 \mathrm{gf}$ and a dwell time of $10 \mathrm{~s}$. The average microhardness values, Hv, were measured along randomly selected diameters on each disk. The analyses by XRD were undertaken using a Bruker D2 Phaser instrument with $\mathrm{Cu}$ radiation $\left(\mathrm{K}_{\alpha 1}=1.54060 \AA\right)$. A Rietveld analysis using MAUD software [15] was performed in order to monitor phase composition, the lattice parameters, $a$, c, the microcrystallite size, $d$ and the microstrain $<\varepsilon^{2}>^{1 / 2}$. Transmission electron microscopy (JEOL) was employed to characterize the fine microstructure of nanostructured titanium processed by HPT. For mechanical testing two miniature tensile specimens were cut from symmetric off-centre positions in each disk [16]. The mechanical properties were examined at room temperature after HPT processing through different numbers of turns and at elevated temperature of $250^{\circ} \mathrm{C}$.

\section{Results and Discussion}

Microhardness. Figure 1 shows results of the microhardness measurements for bulk Ti (Fig. 1a) and HPT-consolidated Ti powder (Fig. 1b). Microhardness of bulk titanium evolves typically for HPT-processed bulk pure metals increasing in 4-5 times with increasing numbers of total revolutions. Powder Ti after pure compression without torsional straining $(\mathrm{P}=6.0 \mathrm{GPa}, \mathrm{N}=0$ and loading time of $1 \mathrm{~min}$ ) and annealing at $700^{\circ} \mathrm{C}$ for $40 \mathrm{~min}$ shows highly inhomogeneous microhardness distribution along the disk diameter. After HPT processing for 5 whole revolutions the microhardness is essentially fully homogeneous and equal to $\mathrm{Hv} \sim 300$, which is very close to the microhardness of the HPT bulk titanium (Fig. 2a) and it is consistent with earlier results [17] where $\mathrm{Hv}$ for consolidated BM titanium powder was $\mathrm{Hv} \sim 350$.

XRD results. Figure 2 summarizes the data on crystallite size and microstrain level in HPT bulk titanium (Fig. 2a) and HPT consolidated powder Ti (Fig. 2b) as a function of annealing

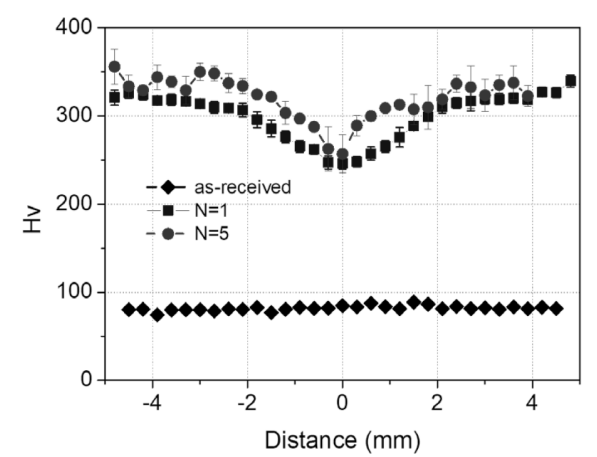

a)

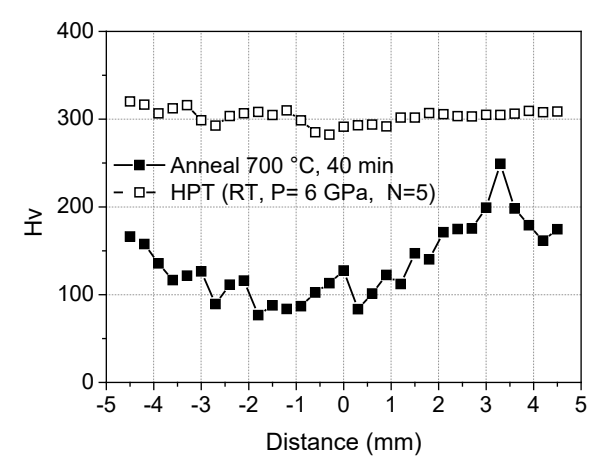

b)

Fig. 1. Microhardness, Hv across the disk diameter in (a) bulk Ti and (b) HPT consolidated titanium powder.

temperature. Bulk titanium subjected to HPT straining underwent a phase transformation and consisted of a mixture of alpha and omega phases. Omega phase has smaller crystallite size $(7.6 \mathrm{~nm})$ and higher microstrain level (0.008). Upon annealing a back transformation occurs and the crystallite size increases to $137 \mathrm{~nm}$ and the microstrain level decreases to 0.0005 . Pre-compacted $\mathrm{Ti}$ powder annealed at $700{ }^{\circ} \mathrm{C}$ for 30 min shows large crystallite size and low microstrain level (Fig. 
2b). After HPT cold consolidation the crystallite size and microstrain become comparable with that for HPT bulk titanium. Under annealing at 250 and $300{ }^{\circ} \mathrm{C}$ for 10 minutes the crystallite size slightly increases and microstrain level drops down to 0.001 .

TEM data. Bright field images of the microstructure are shown in Figure 3 for HPT bulk titanium (Fig. 3a) and HPT consolidated titanium powder (Fig. 3b). Both images show very typical HPT structure for the disk processed at room temperature which consists of grains of $\sim 100 \mathrm{~nm}$ with blurred grain boundaries and typical selected area electron diffraction patterns (SAED) showing rings of diffraction spots. Apparently, the grain size of HPT bulk Ti is a slightly smaller than for HPT-consolidated Ti powder.

Tensile data. Figure 4 summarizes tensile properties for HPT specimens of titanium. Fig. 4a shows the engineering strain-stress curves of HPT bulk titanium tested at room temperature (solid lines) and at elevated temperature (broken lines). Results of testing at room temperature are very typical for HPT pure metals: with increasing accumulated strain, HPT disks demonstrate high tensile strength and low ductility. The disk processed to 5 whole revolutions shows an increase in strength and rather significant decrease in elongation. This can be related to the alpha-omega phase transformation and consequently to the presence of a brittle nanocrystalline omega phase. Tensile testing at $\mathrm{T}=250{ }^{\circ} \mathrm{C}$ shows that strength and elongation of HPT bulk titanium possess similar mechanical behavior. The testing temperature of $250{ }^{\circ} \mathrm{C}$ is higher than the temperature of back omega to alpha phase transformation which is about $175^{\circ} \mathrm{C}$. As one can see there is no unusual mechanical behavior. Additional annealing at $\mathrm{T}=250$ and $300{ }^{\circ} \mathrm{C}$ for 10 minutes leads to decreasing strength as anticipated (Fig. 4b). But one can note significant increase in ductility from less than 0.1 to a value of about 0.3 . Formally it is necessary to consider the strength-ductility paradox. However it can be explained in terms of the omega phase transformation back to nanocrystalline $(\sim 10 \mathrm{~nm})$ alpha phase, which promotes high strength. Figure $4 \mathrm{c}$ shows mechanical behavior of HPT consolidated Ti powder. All specimens, except the sample annealed at $300^{\circ} \mathrm{C}$ for $10 \mathrm{~min}$, show zero ductility. Pre-compacted sample (HPT, $\mathrm{P}=6.0 \mathrm{GPa}, \mathrm{N}=0$, loading for $1 \mathrm{~min}$ ) and annealed at $700^{\circ} \mathrm{C}$ for $40 \mathrm{~min}$ showed an elongation of about 0.006 and a Young's modulus of $88.9 \mathrm{GPa}$ which is noticeably lower than the corresponding results for coarse-grained alpha titanium ( $\sim 110.3 \mathrm{GPa})$. This difference can be attributed to the retained porous structure of the compressed powder titanium. The HPT-consolidated Ti powder processed by torsional straining to five whole revolution showed a Young's modulus of $\sim 136.8 \mathrm{GPa}$

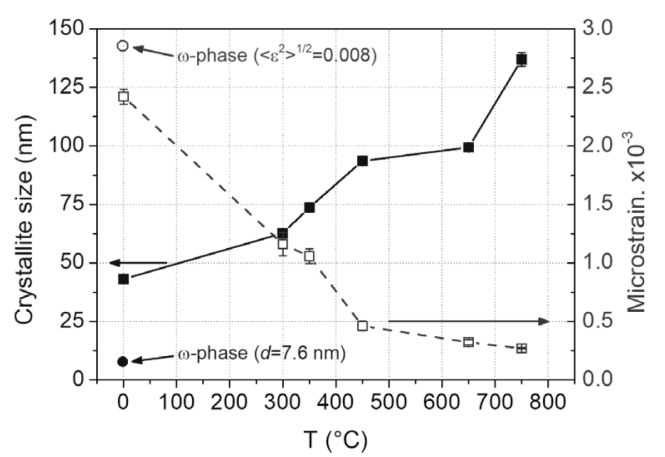

a)

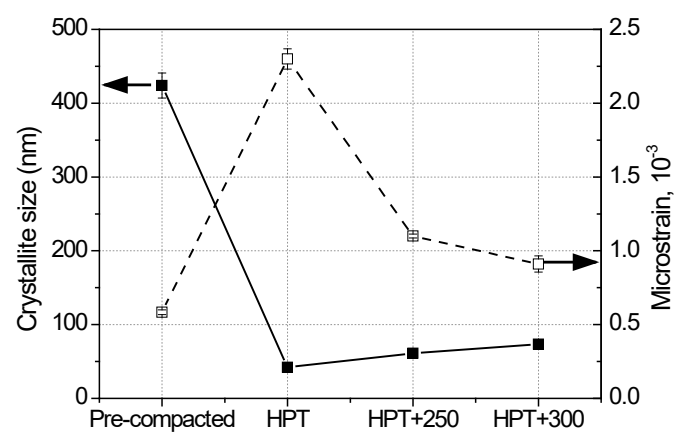

b)

Fig. 2. Crystallite size and microstrain for (a) HPT bulk Ti and (b) HPT-consolidated titanium powder as a function of annealing temperature. 


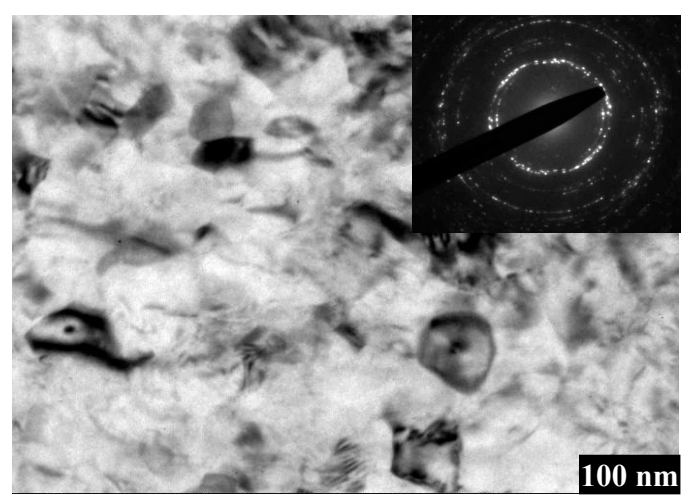

a)

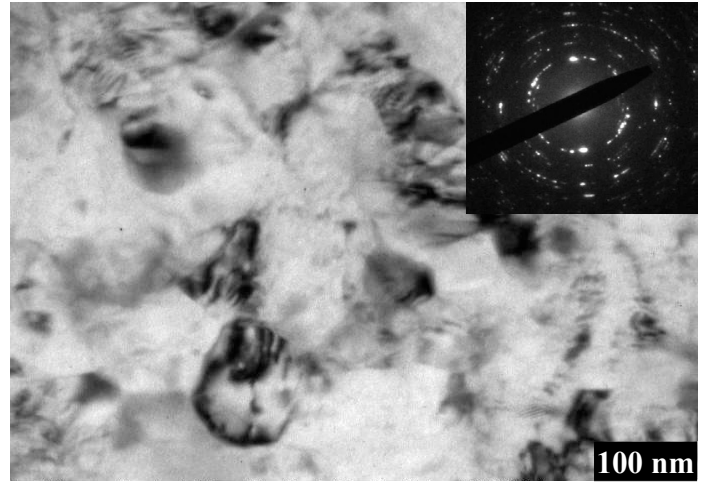

b)

Fig. 3. Bright field TEM of (a) bulk titanium as processed by HPT ( $\mathrm{P}=6 \mathrm{GPa}$ and $\mathrm{N}=5$ ) and (b) Ti powder-consolidated by HPT $(\mathrm{P}=6 \mathrm{GPa}$ and $\mathrm{N}=5)$. Inset depicts $\mathrm{SAED}$.

which is higher than for the coarse-grained material but it is consistent with experimental observations showing that SPD leads in general to an increase in the Young's modulus [18 ]. The increasing Young's modulus for nanostructured materials is related to the high internal stresses induced directly by these processing methods. Conversely, annealing at $250^{\circ} \mathrm{C}$ brings the Young's modulus back to the level of coarse-grained titanium at $117.2 \mathrm{GPa}$. This value of Young's modulus was estimated for the sample annealed at $300^{\circ} \mathrm{C}$. However, it is apparent from Fig. $4 \mathrm{c}$ that this specimen showed enhanced plasticity of $\sim 2.2 \%$. In practice, this is lower than the plasticity of $\sim 8 \%$ reported for the consolidated BM powder subjected to 10 whole revolutions [18]. It is worth noting that, apparently, during HPT straining to 10 revolutions, titanium underwent a reverse omega to alpha phase transformation which can increase the final ductility.

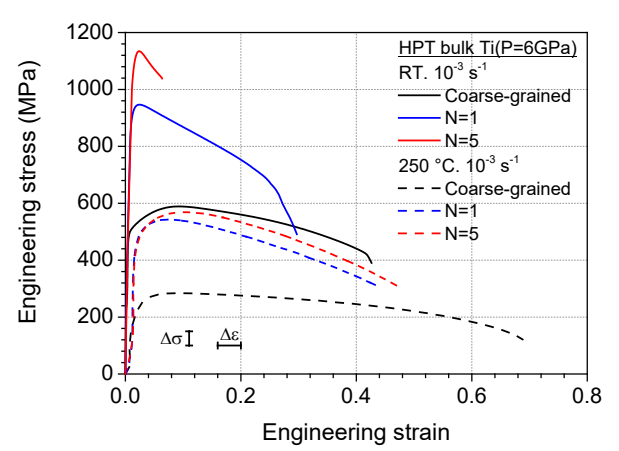

a)

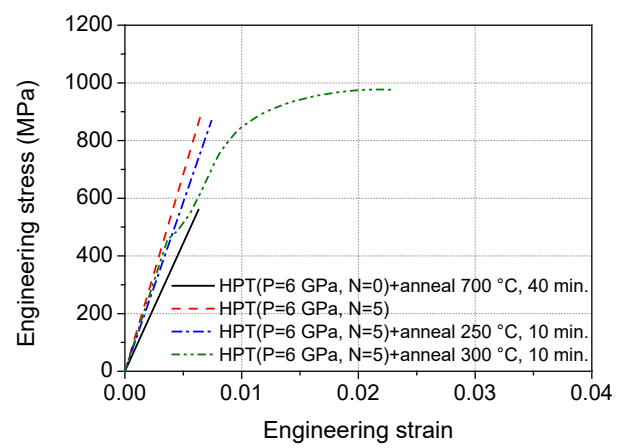

c)

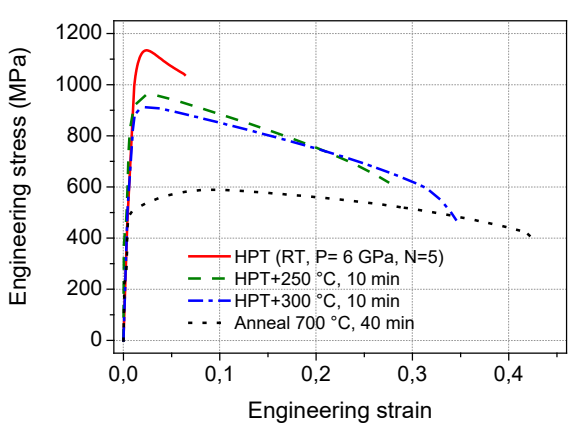

b)

Fig. 4. Engineering stress/strain plots for the bulk HPT titanium tested (a) at RT and at $\mathrm{T}=250{ }^{\circ} \mathrm{C}$; (b) annealed at 250 and $300{ }^{\circ} \mathrm{C}$ for $10 \mathrm{~min}$ and tested at RT. Black lines (solid and dash) are tensile data for the as received samples. Strain rate was $10^{-3} \mathrm{~s}^{-1}$; (c) powder Ti subjected to HPT (RT, $\mathrm{P}=6 \mathrm{GPa}, \mathrm{N}=5$ ) and additional annealing for $10 \mathrm{~min}$ at $\mathrm{T}=250$ and $\mathrm{T}=300{ }^{\circ} \mathrm{C}$.

\section{Summary}

A study of CP bulk and powder titanium processed by HPT revealed that bulk titanium processed by HPT at a load of $6.0 \mathrm{GPa}$ through 5 whole revolutions shows typical mechanical behavior. Short annealing at 250 and $300{ }^{\circ} \mathrm{C}$ for 10 minutes led to a slight decrease in strength and significant increase in ductility when it was tested at room temperature. Testing at elevated temperature 
$\left(250{ }^{\circ} \mathrm{C}\right)$ shows significant decrease in strength and moderate increase in ductility comparable to ductility of coarse-grained titanium tested at room temperature. The consolidated samples had an ultrafine grain size, a nanometer crystallite size, a very high level of internal stress and a correspondingly high dislocation density. As a result, the behavior was generally brittle under tensile testing conditions. Short annealing for 10 minutes at $250^{\circ} \mathrm{C}$ led to a relaxation of the internal stress and no significant (sub)-grain growth. Annealing at the higher temperature of $300^{\circ} \mathrm{C}$ led to a significantly increased ductility up to $\sim 2.2 \%$.

\section{Acknowledgments}

A.P. Zhilyaev gratefully acknowledges financial support from the Ministry of Education and Science of the Russian Federation (Grant 14.Z50.31.0043).

\section{References}

[1] R.Z. Valiev, I.V. Alexandrov, Y.T. Zhu and T.C. Lowe, Paradox of strength and ductility in metals processed by severe plastic deformation. J. Mater. Res., 17(1) (2002) 5-8.

[2] R.Z. Valiev, A.V. Sergueeva, A.K. Mukherjee, The effect of annealing on tensile deformation behavior of nanostructured SPD titanium, Scripta Mater. 49 (2003) 669-674.

[3] X. Wu, F. Yuan, M. Yang, P. Jiang, C. Zhang, L. Chen, Y. Wei, E. Ma, Nanodomained Nickel Unite Nanocrystal Strength with Coarse-Grain Ductility, Sci. Rep. 5 (2015) 11728(1-10).

[4] X. Wu, M. Yang, F. Yuan, G. Wu, Y. Wei, X. Huang, Y. Zhu, Heterogeneous lamella structure unites ultrafine-grain strength with coarse-grain ductility, PNAS 112(47) (2016) 14501-14505.

[5] R.Z. Valiev, Y. Estrin, Z. Horita, T.G. Langdon, M.J. Zehetbauer, Y.T. Zhu, Fundamentals of Superior Properties in Bulk NanoSPD Materials, Mater. Res. Lett. 4(1) (2016) 1-21.

[6] P. Kumar, M. Kawasaki, T.G. Langdon, Review: Overcoming the paradox of strength and ductility in ultrafine-grained materials at low temperatures, J. Mater. Sci. 51 (2016) 7-18.

[7] R.Z. Valiev, A.P. Zhilyaev, T,G, Langdon, Bulk nanostructured materials: Fundamentals and applications. New Jersey: Wiley \& Sons, 2014, 450p.

[8] Y. Wang, M. Chen, F. Zhou, E. Ma, High tensile ductility in a nanostructured metal, Nature 419 (2002) 912-915.

[9] R.Z. Valiev, R.K. Islamgaliev, I.V. Alexandrov, Bulk nanostructured materials from severe plastic deformation, Prog. Mater. Sci. 45 (2000) 103-189.

[10]R.Z. Valiev, T.G. Langdon, Principles of equal-channel angular pressing as a processing tool for grain refinement, Prog. Mater. Sci. 51 (2006) 881-981.

[11]A.P. Zhilyaev, T.G.Langdon, Using high-pressure torsion for metal processing: Fundamentals and applications, Prog. Mater. Sci. 53 (2008) 893-979.

[12]R.Z. Valiev, I. Sabirov, A.P. Zhilyaev, T.G. Langdon, Bulk nanostructured metals for innovative applications, JOM 64(10) (2012) 1134-1142.

[13]R.Z. Valiev, V.Y. Gertsman, O.A. Kaibyshev, On nature of grain boundary recovery, Phys. Stat. Sol. (a) 61 (1980) K95-97.

[14]B-K. Kim, J.A. Szpunar, A.P. Zhilyaev, Annealing texture in thermal stability of ultrafinegrained Ni, Mater. Sci. Forum 408-412(I) (2002) 943-948.

[15] https://imagej.nih.gov/ij/ and http://maud.radiographema.com

[16]A.P. Zhilyaev, G. Ringot, Y. Huang, J.M. Cabrera, T.G. Langdon, Mechanical behavior and microstructure properties of titanium powder consolidated by high-pressure torsion, Mater. Sci. Eng. A 688 (2017) 498-504.

[17]K. Edalati, Z. Horita, H. Fujiwara, K. Ameyama, Cold Consolidation of Ball-Milled Titanium Powders Using High-Pressure Torsion, Metal. Mater. Trans. A 41 (2010) 3308-3317.

[18] G. Wang, X. Li, Predicting Young's modulus of nanowires from first-principles calculations on their surface and bulk materials, J. Appl. Phys. 104 (2009) 113517. 